\title{
Assessing the Effect of Highly Active Anti-Retroviral Treatment and Associated Factors on Incidence of Tuberculosis among Adult HIV Positive Individuals in Assela, Ethiopia
}

Addisu Abebe $^{1 *}$, Belachew Etana ${ }^{2}$, Mache Tsadik ${ }^{2}$ and Wondwossen Terefe ${ }^{3}$

${ }^{1}$ Assella town Health office, Oromia Regional State, Ethiopia

${ }^{2}$ Department of Public Health, Mekelle University College of Health Sciences, Ethiopia

${ }^{3}$ Mekelle University, College of Health Sciences, Department of Public Health, Ethiopia

\begin{abstract}
Background: Study done in Ethiopia in Southern Nation Nationality People (SNNP) during 2003 showed the incidence of TB among those on HAART was lower (3.70 cases of TB per 100 person years) than those, on pre-HAART (11.1 cases of TB per 100 PYO). Besides being on HAART or pre HAART different socio demographic, substance use and clinical factors play an important role in developing TB infection among PLHIV. So, the objective of this study was to assess the effect of HAART on incidence of TB among people living with HIVIAIDS. 1.2 Methods: A retrospective cohort study was conducted at Assela referral Hospital among patients enrolled on HIV care and support during September 13/2005 to January 30/2011. A total of 412 patients' record from the HAART and pre HAART group were selected in one to one ratio by simple random sampling method. Kaplan Meier and proportional cox regression methods were used to determine the predictor of TB incidence.
\end{abstract}

Result: The incidence of tuberculosis was $7.02 / 100$ person years (95\% Cl: $5.02,9.83)$ among those on pre HAART follow up where as it was 3.73/100 person years among those on HAART. Furthermore, individuals on HAART have a $96.8 \%$ decrease in risk of tuberculosis, (AHR $=0.032 ; 95 \% \mathrm{Cl}: 0.012,0.082)$ than those non-HAART individuals. Similarly CD4 cell count $<200$ cell/ $\mu$ land WHO clinical stage III or IV has statistically significant association with TB development among People living with HIVIAIDS.

Conclusion and recommendation: HAART use decreased tuberculosis incidence among HIV positive individuals. In addition, CD4 cell count $<200 \mathrm{cell} / \mu \mathrm{l}$ and WHO clinical stage III or IV were factors associated with the development of new TB cases among PLHIV. So, HAART should be started with a higher CD4 cell count and none advanced WHO clinical stage in order to get maximum reduction of new TB cases among PLHIV.

Keywords: Tuberculosis; Anti-retroviral treatment; HIV positive

\section{Introduction}

Tuberculosis (TB), one of the infectious diseases known to affect humans, is a major cause of death worldwide. It is commonly caused by Mycobacterium tuberculosis [1]. Tuberculosis and HIV are among the leading killer infectious disease in the developing world. These diseases are life threatening by their own, but the risk is becoming more severe as a large number of people infected with HIV are also infected by TB $[2,3]$. In Ethiopia, about $41 \%$ TB diagnosed individuals were found to be HIV positive in 2007 and the TB-HIV co infection rate was $31 \%$ in the same year $[3,4]$. Highly active antiretroviral treatment (HAART) is the cornerstone in the management of HIV infection; where the primary goal is preventing HIV-related morbidity and improving quality of life, reducing mortality and maximally suppress viral load [5].

Different studies showed use of HAART decreases risk of having TB among PLHIV [6-9]. A prospective cohort study done in south Africa revealed that TB incidence was lower among PLHIV taking HAART than pre HAART; 2.4 versus 9.7 cases of TB per 100 patient year [10]. Similar Finding was also obtained both in high income and low income countries showed that PLHIV on HAART had lower rate of incidence TB as compared to PLHIV on pre HAART care [713]. In Ethiopia studies have showed that, incidence of TB is higher among patient on pre-HAART than those on HAART. Two different studies done in South Africa and Southern Nation Nationality People (SNNP) it was found to be higher in both groups $[10,14]$. In contrast to this, study from South Africa reported that HAART doesn't decrease incidence TB among treated PLHIV when compared with HIV negative individuals [15]. Factors associated with TB infection were varied and different among People Living with HIV. The first and the most important are being on treatment using anti-retroviral therapy. According to meta-analysis done on HAART in developing countries HAART can significantly decrease TB infection among PLHIV [16]. This finding was also supported by studies done in Brazi, United States and Denmark $[7,9,11,12,17]$. Besides, studies has also found that, the lower base line CD4 cell count and at advanced WHO staging of HIV of individuals also contributes to the development of TB among PLHIV $[10,12,18-23]$. Furthermore lower base line hemoglobin level $(<12 \mathrm{~g} / \mathrm{dl})$ and base line Body Mass Index (BMI) less than $18.5 \mathrm{~kg} / \mathrm{m}^{2}$ was also shown to have an association with TB infection $[18,21,23,24]$. Sociodemographic factors have association with TB infection In addition to clinical factors. It was found that male sex, patients at older age and those from urban were at higher risk to develop TB [8,10,18,21-27]. There are contrasting results in association between $\mathrm{TB}$ infection and illicit drug use. According to study done in Brazil, generally illicit drug uses were found to be associated with increased risk of TB infection

*Corresponding author: Addisu Abebe, Assella town Health office, P.O. Box 36, Assela, Oromia Regional State, Ethiopia, Tel: +251223315997; E-mail: addishiwot2001@gmail.com

Received May 13, 2014; Accepted May 29, 2014; Published May 31, 2014

Citation: Abebe A, Etana B, Tsadik M, Terefe W (2014) Assessing the Effect of Highly Active Anti-Retroviral Treatment and Associated Factors on Incidence of Tuberculosis among Adult HIV Positive Individuals in Assela, Ethiopia. J Health Med Informat 5: 156. doi:10.4172/2157-7420.1000156

Copyright: ( 2014 Abebe A, et al. This is an open-access article distributed under the terms of the Creative Commons Attribution License, which permits unrestricted use, distribution, and reproduction in any medium, provided the original author and source are credited. 
Citation: Abebe A, Etana B, Tsadik M, Terefe W (2014) Assessing the Effect of Highly Active Anti-Retroviral Treatment and Associated Factors on Incidence of Tuberculosis among Adult HIV Positive Individuals in Assela, Ethiopia. J Health Med Informat 5: 156. doi:10.4172/21577420.1000156

Page 2 of 5

among PLHIV [25,28]. But another study showed alcohol use, smoking and chat chewing not associated with development of TB [18].

Generally many of the previous studies done in other countries reported that HAART use reduces TB incidence among PLHIV, but there are contrasting result how it can decrease TB infection. Studies that have been done in Ethiopia focuses predominantly on adherence to wards HAART and its survival benefit and there is limited evidence about whether HAART has a significant effect on the incidence TB. Given that Ethiopia is a country with high HIV-TB co infection; little was done to address this problem among PLHIV $[2,10]$. Therefore, the aim of this study was to assess if there is difference in TB incidence among PLHIV by their HAART status. In addition this study also conducted to identify factors associated with TB infection in Assela referral hospital. So that, it provide an evidence for policy makers and program managers working on HIV/AIDS and TB programs for better planning and design of program related to these two diseases.

\section{Method}

\section{Study area and population}

The study was conducted in Assela referral Hospital which is found $175 \mathrm{kms}$ from Addis Ababa the capital of, Ethiopia. The study enrolled PLHIV on HAART and pre HAART which were under follow up care from September 13/ 2005 up to January 30/2011. A total of 3271 PLHIV on HAART and 2217 PLHIV on pre HAART care were identified. The study participants were included if they were between 15-64 years of age. In addition they were diagnosed for HIV between September $13 / 2005$ to January 30/2011. Clients who were tested for HIV at other health facility (Transfer in), those diagnosed with TB and HIV, PLHIV taking anti TB at the time of enrollment were excluded from the study.

\section{Sample size determination and Sampling procedure}

Sample size was determined using STATA version 12 software using sample size calculation for cox proportional hazard model. The $80 \%$ power, $5 \%$ significance level and standard deviation 0.5 were assumed for sample size calculation. To select study participants first their medical record number (MRN) and unique ART number of PLHIV were used from the HIV data base. Finally, study subjects were selected by simple random sampling method, after the two groups have been provided an increasing sequential number independently, using random numbers generated by computer.

\section{Data collection}

Data was collected from routinely collected paper based data primarily for care and treatment of PLHIV in Assela Referral Hospital ART clinic. Data collection took place from March 11-26/2013 by two data collectors from Assela Hospital ART clinic. And it was supervised by health professional from Assela health center ART clinic. Training was given for both data collector and supervisor on the study objective, data collection tool and on how to retrieve data from the patient record. Check list was prepared from intake form, follow up forms and other clinical records of patient. To check the logical order and understandability of the questionnaire a pretest was conducted on 5\% of the sample at Assela Health center ART clinic. And data quality was maintained by close supervisor and some of the questionnaire was crosschecked with the patient registration.

\section{Statistical analysis}

The collected data were coded, entered, cleaned and analyzed in STATA version 12 (College Station, Texas 77845 USA). Tuberculosis free survival probability was determined both unadjusted and adjusted Kaplan Meier curve. It was calculated by HAART use status and by other explanatory variables found significant at the log rank test. Incidence rate of TB was calculated as number of TB cases per 100 person years of observation (PYO) by HAART use status. The incidence rate between the two groups was compared by adjusted hazard ratio. To identify predictors of TB incidence a multivariate Cox proportional Hazard model was built with purposeful selection of covariates and back ward elimination method by taking variables with $p$ value $\leq 0.25$ during the bivariate analysis. Variables were retained in the multivariate model if it showed a significant effect ( $p$ value $\leq 0.05$ ) in Wald chi squared test. Presence of potential confounder was assessed using change in the coefficients $(\beta)$. Interaction among variables was checked by creating interaction terms and using $\mathrm{p}$ values from log likelihood ratio test. Plots of Schoenfeld residuals and tests of Schoenfeld residual using global test was used to assess the proportionality hazard assumption. DFBETA were used to handle influential observations. Finally, the sufficiency of the fitted model to the survival data was checked using Nelson Aalen cumulative hazard estimator for Cox-Snell residuals.

Survival analysis for PLHIV on HAART was the time from registration on the ART log book till date of TB diagnosis, (LTFU) or drop out, death, transfer to other health facility (TO) or the person was alive and the study ended which ever come first. Similarly for PLHIV on pre HAART follow up were the time from registration in the pre HAART log book until TB diagnosis, LTFU (drop out), dead, TO, or a person was alive and the study ended.

\section{Ethical clearance}

Ethical clearance was obtained from Mekelle University (MU) College of Health Science (CHS) Ethical Review Committee. Formal letter for cooperation was secured from Oromiya Regional Health Bureau and Administration office of Assela referral Hospital. Each study subjects' record was coded and on the data collection tool patient name and personal address was not written.

\section{Results}

\section{Baseline characteristics of study subjects}

A total of 412 PLHIV, 206 from the pre HAART care and 206 on HAART were included in the study. From the study subjects on HAART 105 (50.97\%) of them were female and the corresponding number for pre HAART were 141 (68.45\%) (Table 1). Besides this, a majority of the study subjects in both group was in the age group of 3039 years $98(47.57 \%)$ and $85(41.26 \%)$ in the HAART and pre HAART group respectively. Furthermore, a majority, 135 (65.53\%), of study subjects on HAART had a CD 4 cell count of $<200$ cells/ $\mu$ l whereas 109 (52.91\%) of study subjects on pre HAART had a CD4 cell count of $\geq$ 350 cells/ $\mu \mathrm{l}$ (Table 1$)$. A higher number of study subjects, $149(72.33 \%)$ on HAART were categorized under WHO clinical stage III or IV while, $164(79.61 \%)$ of study subjects on pre HAART follow up were categorized under WHO clinical stage I or II (Table 1).

\section{Incidence rate of TB by HAART use}

Study subjects on HAART were followed for 34.38 ; (IQR=50.8013.23) months, while those on pre HAART were followed 26.45 $(\mathrm{IQR}=41.86-11.33)$ months in average. During this period 22 new case of TB was diagnosed from total of 589.98 person year from HAART group. Similarly 34 new TB case were diagnosed from the total 484.18 person year. Accordingly the incidence rate of TB among HIV positive individuals on HAART was 3.73 cases of TB per 100 PYO while it was 
Citation: Abebe A, Etana B, Tsadik M, Terefe W (2014) Assessing the Effect of Highly Active Anti-Retroviral Treatment and Associated Factors on Incidence of Tuberculosis among Adult HIV Positive Individuals in Assela, Ethiopia. J Health Med Informat 5: 156. doi:10.4172/21577420.1000156

Page 3 of 5

\begin{tabular}{|c|c|c|c|c|}
\hline Variable & & HAART n (\%) & Pre HAART n (\%) & Total n (\%) \\
\hline \multirow[t]{2}{*}{ Sex } & Male & $101(49.03)$ & 65 (31.55) & $166(40.29)$ \\
\hline & Female & $105(50.97)$ & $141(68.45)$ & $246(59.71)$ \\
\hline \multirow[t]{3}{*}{ Age } & $15-29$ & $45(21.85)$ & 72 (34.95) & $114(27.67)$ \\
\hline & $30-39$ & $98(47.57)$ & $85(41.26)$ & $186(45.15)$ \\
\hline & $>39$ & $63(30.58)$ & 49 (23.79) & $112(27.18)$ \\
\hline \multirow{3}{*}{$\begin{array}{l}\text { CD4 cell count } \\
\text { (in cells/ } \mu \mathrm{l} \text { ) }\end{array}$} & $<200$ & $135(65.53)$ & $11(5.34)$ & $146(35.44)$ \\
\hline & $200-349$ & $64(31.07)$ & $86(41.75)$ & $150(36.41)$ \\
\hline & $\geq 350$ & $7(3.40)$ & $109(52.91)$ & $116(28.15)$ \\
\hline \multirow{2}{*}{$\begin{array}{l}\text { WHO clinical } \\
\text { STAGE }\end{array}$} & Stage III or IV & $149(72.33)$ & $42(20.39)$ & $191(46.36)$ \\
\hline & Stage I or II & $57(27.67)$ & $164(79.61)$ & $221(53.64)$ \\
\hline
\end{tabular}

\section{Discussion}

This study was done to assess the effect of HAART on incidence and free TB survival and associated risk factors among adult PLHIV under chronic HIV care in Assela referral hospital Ethiopia. We found that the incidence rate of TB is lower among PLHIV on HAART as compared to PLHIV on pre HAART. This result is in agreement with studies conducted in SNNP of Ethiopia at Arbaminch Hospital and in South Africa where the incidence rate of TB for PLHIV on HAART were lower than the corresponding incidence rate of TB among PLHIV on pre HAART care $[10,14]$. The decrease in incidence rate of TB is because use of HAART is associated with a marked increase in survival of PLHIV, as it improves immune condition and decreases risk of opportunistic infection [6].

Others similar findings with our study were obtained in high income countries; United States and Denmark $[9,12]$. The study in United State reported that, incidence rate of TB among PLHIV on HAART (135 cases of TB per 100,000 PYO) were significantly lower than the incidence rate of TB among PLHIV on pre HAART (212 cases of TB per 100,000 PYO) [9]. Similarly findings from Denmark showed that incidence rate of TB among PLHIV on HAART ( 6.5 cases of TB per 1000 PYO) were lower than the incidence among the pre HAART (37.1 cases of TB per 1000 PYO) [12].

But as compared to both studies from Denmark and United States $[9,12]$, higher number of incidence rate of TB was observed in both groups in the current study. This may be because the current study was conducted in the state of high TB burden country, where Ethiopia is among the $22 \mathrm{HBC}$ of TB in the world [2]. But as described in other study $[13,20]$, small number of TB incidence among PLHIV in HBC of TB can be achieved by early initiation of HAART and integration with IPT $[6,16]$, which will bring restoration of the immune system and suppression of latent TB infection resulting in good TB control. This can be further improved by long term use of HAART where the TB incidence rate will be lowered to less than 1 cases of TB per 100 PYO [20].

When we see the incidence rate of TB for PLHIV on HAART in our study in relation with other studies, it is comparable with finding from SNNP of Ethiopia (14). However, the incidence rate is higher when compared to the findings from South Africa (2.4 cases of TB per 100 PYO). This difference might be due to $72.33 \%$ of study subjects on HAART in the current study were presented with WHO clinical stage (III or IV) while only $46 \%$ of the study subjects, from South Africa, were presented with WHO clinical stage (III or IV) [10].

In our study although PLHIV enrolled on pre HAART care had relatively higher incidence rate of TB than those on HAART. This finding is lower when compared with finding from SNNP of Ethiopia (and South Africa (9.70 cases per 100 PYO) $[10,14]$. This might be due to majority of PLHIV on pre HAART in our study were presented with WHO clinical stage I or II (79.61\%). But, study participants of those from SNNP of Ethiopia were majorly presented with WHO clinical stage III [14]. Similarly, majority of PLHIV on pre HAART in our study had a baseline CD4 cell count $\geq 350$ cells/ $\mu$ l, while those from the South African study had a CD4 cell count of $<350$ cells/ $\mu$ lat base line [10].

Regarding the free TB survival, the probability of free TB survival was higher for PLHIV on HAART as compared to PLHIV on pre HAART care. This result is consistent with the findings from SNNP 
Citation: Abebe A, Etana B, Tsadik M, Terefe W (2014) Assessing the Effect of Highly Active Anti-Retroviral Treatment and Associated Factors on Incidence of Tuberculosis among Adult HIV Positive Individuals in Assela, Ethiopia. J Health Med Informat 5: 156. doi:10.4172/21577420.1000156

Page 4 of 5

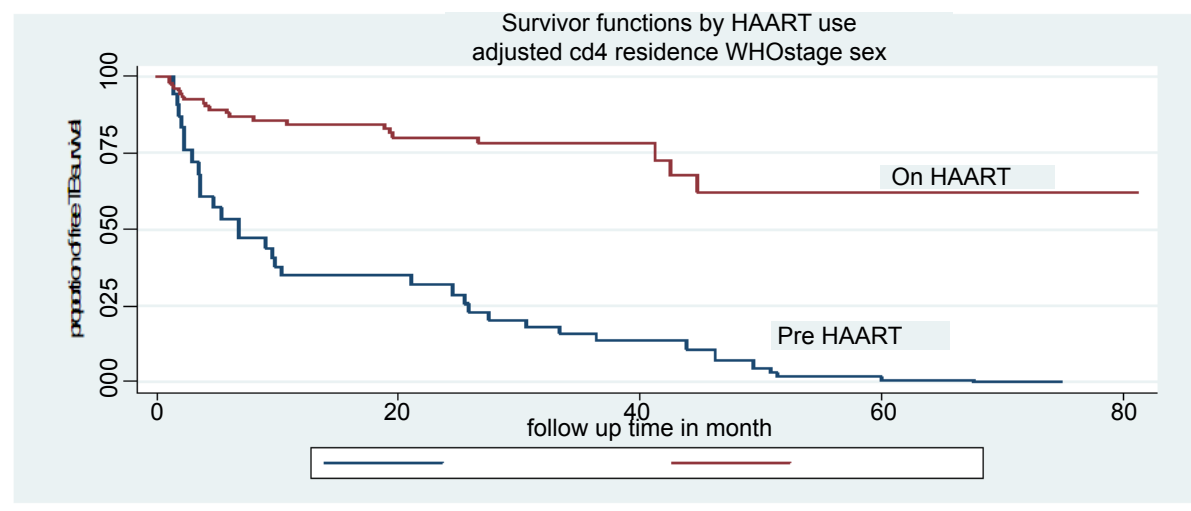

Figure 1: Survival curves by HAART use for CD4 cell count, sex, residence, WHO clinical stage.

of Ethiopia, South Africa and two studies from Brazil [6,10,14,17]. The better free TB survival for PLHIV on HAART might be due to; persistent inhibition of HIV viral replication that results immune boosting and protection from TB infection. But for PLHIV on pre HAART as they stayed long time on pre HAART care their immunity become depleted and leads to increase in incidence TB from the latent TB infection [1,5]. Moreover the decrease in probability of free TB survival among PLHIV on pre HAART might be due to recent transmission of TB.

Generally, the current study has identified that PLHIV on HAART had lower rate of developing TB as compared with PLHIV on pre HAART. The result is consistent with previous study reports from SNNP of Ethiopia, South Africa and Brazil $[10,11,14]$. However, the decrease in TB incidence among PLHIV on HAART in our study is higher than the decrease in high income countries (six European countries and United States) [7]. This might be due to low TB incidence in the general communities and low previously un-diagnosed TB among PLHIV in high income countries limits the effect of HAART [9].

As described in many studies [12,18-22]; in our study PLHIV having a base line CD4 cell count of $<200$ cells/ $\mu$ l were having an increased rate of developing TB as compared to those having a CD4 cell count of 200-349 and $\geq 350$ cells/ $\mu l$. The increased rate of incidence TB among PLHIV with a baseline CD 4 cell count of $<200$ cells/ $\mu \mathrm{lmight}$ be due to advanced pre enrollment immunodeficiency that limits the extent to which immune function can be restored thereby increasing TB incidence from the latent TB [20]. Similarly PLHIV presented with WHO clinical stage (III or IV) were having increased rate of developing $\mathrm{TB}$ as compared with those PLHIV presented with WHO clinical stage (I or II). The result is in agreement with two different studies from South Africa [10,23].

The limitation of this study includes; due to the use of record review, although it was adjusted for CD4 cell count, sex, residence, WHO clinical stage; the association between HAART use and incidence TB could be confounded by other factors not included in the analysis such as house hold income and housing condition. Besides this, occupational status and past history of TB were not included in the analysis due to missed data in most of the documents. Incidence rate of TB might also be underestimated due to lost to follow up, transfer out and dead study subjects, because these patients probably includes more individuals developing TB.

\section{Conclusions and Recommendations}

In general HAART use was found to decrease tuberculosis incidence. People living with HIV/AIDS on HAART had better free
TB survival as compared to pre HAART CD4 cell count $<200$ cells/ $\mu \mathrm{l}$, being on pre HAART care and WHO clinical stage III or IV were the independent risk factors for developing TB. So HAART should be started with a higher CD4 cell count and none advanced WHO clinical stage in order to get maximum reduction of incidence TB with strong evaluation of its cost effectiveness and issue of adherence. TB Screening should be done for all PLHIV, but special focus is needed for PLHIV with the risk factors identified in this study.

\section{Authors' Contributions}

AA, BE, MT and WT designed the study. AA followed the patients. $\mathrm{AA}, \mathrm{BE}, \mathrm{MT}$ and WT analyzed the data. AA and BE drafted the manuscript and approved the final version.

\section{Acknowledgements}

We thank Mekelle University, Tulane international, Oromiya regional health Bureau for giving us an opportunity to conduct this study.

\section{References}

1. Fauci A, Braunwald E, Kasper D, Hauser S, Longo D, et al. (2008) Harrison's Principles of Internal Medicine. $17^{\text {th }}$ edition, The McGraw-Hill Companies, Inc.

2. World health organization (2013) Global Tuberculosis report: 2012.

3. Federal Ministry of Health of Ethiopia (2013) Implementation Guideline for TB/ HIV Collaborative Activities in Ethiopia.

4. Central Statistical Agency (2012) Ethiopia Demographic and Health Survey 2011. Addis Ababa, Ethiopia, ICF International Calverton, Maryland, USA.

5. Panel on Antiretroviral Guidelines for Adults and Adolescents (2013) Guidelines for the use of Antiretroviral agents in HIV-1 infected adults and adolescents. The Department of Health and Human Services.

6. Batista Jd, de Albuquerque Mde F, Maruza M, Ximenes RA, Santos ML, et al. (2013) Incidence and risk factors for tuberculosis in people living with HIV: cohort from HIV referral health centers in Recife, Brazil. PLoS One 8: e63916.

7. HIV-CAUSAL Collaboration (2012) Impact of antiretroviral therapy on tuberculosis incidence among HIV-positive patients in high-income countries. Clin Infect Dis 54: 1364-1372.

8. Muga R, Ferreros I, Langohr K, de Olalla PG, Del Romero J, et al. (2007) Changes in the incidence of tuberculosis in a cohort of HIV-seroconverters before and after the introduction of HAART. AIDS 21: 2521-2527.

9. Pettit AC, Jenkins CA, Stinnette SE, Rebeiro PF, Blackwell RB, et al. (2011) Tuberculosis risk before and after highly active antiretroviral therapy initiation: does HAART increase the short-term TB risk in a low incidence TB setting? J Acquir Immune Defic Syndr 57: 305-310.

10. Badri M, Wilson D, Wood R (2002) Effect of highly active antiretroviral therapy on incidence of tuberculosis in South Africa: a cohort study. Lancet 359: 2059 2064. 
Citation: Abebe A, Etana B, Tsadik M, Terefe W (2014) Assessing the Effect of Highly Active Anti-Retroviral Treatment and Associated Factors on Incidence of Tuberculosis among Adult HIV Positive Individuals in Assela, Ethiopia. J Health Med Informat 5: 156. doi:10.4172/21577420.1000156

Page 5 of 5

11. Miranda A, Morgan M, Jamal L, Laserson K, Barreira D, et al. (2007) Impact of antiretroviral therapy on the incidence of tuberculosis: the Brazilian experience 1995-2001. PLoS One 2: e826.

12. Taarnhøj GA, Engsig FN, Ravn P, Johansen IS, Larsen CS, et al. (2011) Incidence, risk factors and mortality of tuberculosis in Danish HIV patients 1995-2007. BMC Pulm Med 11: 26.

13. Lawn SD, Bekker LG, Wood R (2005) How effectively does HAART restore immune responses to Mycobacterium tuberculosis? Implications for tuberculosis control. AIDS 19: 1113-1124.

14. Jerene D, Naess A, Lindtjørn B (2006) Antiretroviral therapy at a district hospita in Ethiopia prevents death and tuberculosis in a cohort of HIV patients. AIDS Res Ther 3: 10.

15. Gupta A, Wood R, Kaplan R, Bekker LG, Lawn SD (2012) Tuberculosis incidence rates during 8 years of follow-up of an antiretroviral treatment cohort in South Africa: comparison with rates in the community. PLoS One 7: e34156.

16. Suthar AB, Lawn SD, del Amo J, Getahun H, Dye C, et al. (2012) Antiretrovira therapy for prevention of tuberculosis in adults with HIV: a systematic review and meta-analysis. PLoS Med 9: e1001270.

17. Lannoy LH, Cortez-Escalante JJ, Evangelista Mdo S, Romero GA (2008) Tuberculosis incidence and risk factors among patients living with HIVIAIDS in public health service institutions in Brasilia Federal district. Rev Soc Bras Med Trop 41: 549-555.

18. Taha M, Deribew A, Tessema F, Assegid S, Duchateau L, et al. (2011) Risk Factors of Active Tuberculosis in People Living with HIVIAIDS in Southwest Ethiopia: A Case Control Study. Ethiop J Health Sci 21: 131-139.

19. Sterling TR, Lau B, Zhang J, Freeman A, Bosch RJ, et al. (2011) Risk factors for tuberculosis after highly active antiretroviral therapy initiation in the United States and Canada: implications for tuberculosis screening. J Infect Dis 204: 893-901.

20. Lawn SD, Badri M, Wood R (2005) Tuberculosis among HIV-infected patients receiving HAART: long term incidence and risk factors in a South African cohort. AIDS 19: 2109-2116.

21. Auld AF, Mbofana F, Shiraishi RW, Alfredo C, Sanchez M, et al. (2013) Incidence and determinants of tuberculosis among adults initiating antiretroviral therapyMozambique, 2004-2008. PLoS One 8: e54665.

22. Hermans SM, Kiragga AN, Schaefer P, Kambugu A, Hoepelman Al, et al. (2010) Incident tuberculosis during antiretroviral therapy contributes to suboptimal immune reconstitution in a large urban HIV clinic in Sub-Saharan Africa. PLoS One 5: e10527.

23. Komati S, Shaw PA, Stubbs N, Mathibedi MJ, Malan L, et al. (2010) Tuberculosis risk factors and mortality for HIV-infected persons receiving antiretrovira therapy in South Africa. AIDS 24: 1849-1855.

24. Choun K, Thai S, Pe R, Lorent N, Lynen L, et al. (2013) Incidence and risk factors for tuberculosis in HIV-infected patients while on antiretroviral treatment in Cambodia. Trans R Soc Trop Med Hyg 107: 235-242.

25. Silveira JM, Sassi RA, de Oliveira Netto IC, Hetzel JL (2006) Prevalence and factors related to tuberculosis in seropositive human immunodeficiency virus patients at a reference center for treatment of human immunodeficiency virus in the southern region of the state of Rio Grande do Sul, Brazil. J Bras Pneumo 32: $48-55$

26. Seyler C, Toure S, Messou E, Bonard D, Gabillard D, et al. (2005) Risk factors for active tuberculosis after antiretroviral treatment initiation in Abidjan. Am J Respir Crit Care Med 172: 123-127.

27. Nicholas S, Sabapathy K, Ferreyra C, Varaine F, Pujades-Rodríguez M (2011) Incidence of tuberculosis in HIV-Infected Patients before and after Starting combined antiretroviral Therapy in 8 Sub-Saharan African HIV Programs. Acquir Immune Defic Syndr 57: 311-318.

28. Cohn SE, Jiang H, McCutchan JA, Koletar SL, Murphy RL, et al. (2011) Association of ongoing drug and alcohol use with non-adherence to antiretrovira therapy and higher risk of AIDS and death: results from ACTG 362. AIDS Care 23: $775-785$ 